\title{
Compositional Engineering of Halide Perovskites
}

Qinyi $\mathrm{Li}^{1,2 *}$

Received date: 15 February 2021; Accepted date: 27 February 2021.

Article type: Highlight.

Nowadays, silicon-based photovoltaic (PV) panels that directly convert sunlight into electricity have been commercially available for both individual buildings and small-scale power plants. However, the production of crystalline silicon PV modules consumes a lot of energy and fossil fuels, thus the whole life cycle of silicon solar cells is not as green as you think. Therefore, researchers have been exploring low-cost and energy-efficient non-silicon-based PV technologies for decades, among which the halide perovskitebased PV quickly stood out and has attracted tremendous research efforts due to its simple solution-based fabrication and competitive power conversion efficiency (PCE). Pioneered by Prof. Tsutomu Miyasaka and colleagues from Toin University of Yokohama in Japan in $2009,,^{[1,2]}$ the labscale halide perovskite PV device has witnessed a PCE enhancement from $3.8 \%$ to above $20 \%$, which is comparable to silicon, during just one decade.

Currently, the commercialization of halide perovskite solar cells is hindered by two profound issues. ${ }^{[2]}$ The first obstacle is the long-term instability under operational conditions involving atmospheric moisture, raised temperature, and real sunlight. For example, $\mathrm{CH}_{3} \mathrm{NH}_{3} \mathrm{PbI}_{3}$, a typical high-efficiency perovskite PV material, degrades easily at $120{ }^{\circ} \mathrm{C} .{ }^{[2]}$ Second, the high-efficiency perovskites contain the toxic lead element, which can potentially harm the environment and human health and thus has been a major concern for commercialization. Many efforts have been devoted to addressing these issues. Especially, the compositional tuning of the perovskites, like the mixing of cations and anions, has led to remarkable improvements. At present, further research in the direction of compositional engineering is urgently desired to balance the stability, efficiency, and toxicity issues of perovskites.

\footnotetext{
${ }^{1}$ Department of Aeronautics and Astronautics, Kyushu University,

744 Motooka, Fukuoka 819-0395, Japan.

${ }^{2}$ International Institute for Carbon-Neutral Energy Research (WPII2CNER), Kyushu University, 744 Motooka, Fukuoka 819-0395, Japan.

*Email: qinyi.li@aero.kyushu-u.ac.jp
}

In this issue, we have two articles on halide perovskites with non-traditional compositions. Bhorde et al. ${ }^{[3]}$ incorporated $\mathrm{Rb}$ in Bi-based double perovskite and synthesized $\mathrm{Rb}_{2} \mathrm{AgBiI} \mathrm{I}_{6}$ perovskite thin films for the first time. This lead-free halide double perovskite showed a bandgap of about $1.98 \mathrm{eV}$ and superior thermal stability at a temperature as high as $440{ }^{\circ} \mathrm{C}$, which indicates promising applications in non-toxic and thermally-stable perovskite photovoltaics and optoelectronics. Jathar et al. ${ }^{[4]}$ report a facile synthesis method of an inorganic metal halide perovskite, $\mathrm{CsPbBr}_{3}$, which could help accelerate the synthesis of compositionally adjusted perovskites.

Besides the perovskite research, this issue also collects articles on the compositional engineering of other important materials. The $(\mathrm{Gd}, \mathrm{Y}) \mathrm{AG}: \mathrm{Ce}^{3+}$ based phosphors have attracted much attention because of the excellent yellow light emission properties. Ma et al. ${ }^{[5]}$ partly substituted $\mathrm{Al}^{3+}$ in $(\mathrm{Gd}, \mathrm{Y}) \mathrm{AG}: \mathrm{Ce}^{3+}$ by $\mathrm{Ga}$ or $\mathrm{Mg}, \mathrm{Si}$ ions, and observed tunable color emission as the concentrations of the compositions changed. As for ceramic composites, Yang et al.$^{[6]}$ added $0.3 \%$ content of graphene platelets to the $\mathrm{Si}_{3} \mathrm{~N}_{4} / \mathrm{SiC}$ ceramics. Because of the crack deflection induced by the graphene additive, the fracture strength of the ceramic was enhanced by up to $35 \%$.

These continuing efforts of controlling materials properties by adjusting the compositions have witnessed great success in the history of materials research. In the future, the acceleration of the discovery of superior materials will require the development of faster synthesis methods, high-throughput properties characterization, as well as the incorporation of machine learning and AI.

\section{References}

[1] A. Kojima, K. Teshima, Y. Shirai, T. Miyasaka, J. Am. Chem. Soc., 2009, 131, 6050-6051, doi: 10.1021/ja809598r.

[2] A. K. Jena, A. Kulkarni, and T. Miyasaka, Chem. Rev., 2019, 119, 3036-3103, doi: 10.1021/acs.chemrev.8b00539.

[3] A. Bhorde, R. Waykar, S. C. Rondiya, S. Nair, G. Lonkar, A. Funde, N. Y. Dzade, S. Jadkar, ES Mater. Manuf., 2021, 12, doi: 10.30919/esmm5f1042. 
[4] S. B. Jathar, S. R. Rondiya, B. R. Bade, M. P. Nasane, S. V. Publisher's Note Engineered Science Publisher remains Barma, Y. A. Jadhav, A. V. Rokade, K. B. Kore, D. S. Nilegave, neutral with regard to jurisdictional claims in published maps P. U. Tandale, S. R. Jadkar, A. M. Funde, ES Mater. Manuf., 2021, and institutional affiliations.

12, doi: 10.30919/esmm5f1036.

[5] S. Ma, B. Liu, B. Cao, Y. Lu, Z. Liu, ES Mater. Manuf., 2021, 12, doi: 10.30919/esmm5f920.

[6] H. Yang, Q. Li, Z. Wang, H. Wu, Y. Wu, P. Hou, X. Cheng, ES Mater. Manuf., 2021, 12, doi: 10.30919/esmm5f418.

\section{Author information}

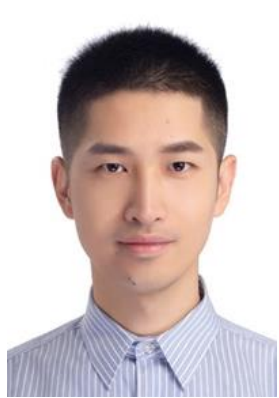

Qinyi Li obtained his B. Eng. and Dr. Eng. from Tsinghua University, in 2011 and 2016, respectively. After that, he joined Kyushu University and has been working as an assistant professor. His research interests are focused on nanoscale heat and mass transfer, thermoelectric energy conversion, and other clean energy technologies. 